Poultry as reservoir hosts for fishborne zoonotic trematodes in vietnamese fish farms

Anh, Nguyen Thi Lan; Madsen, Henry; Dalsgaard, Anders; Phuong, Nguyen Thi; Thanh, Dao Thi Ha; Murrell, Kenneth Darwin

Published in:

Veterinary Parasitology

DOI:

10.1016/j.vetpar.2010.01.010

Publication date:

2010

Document version

Publisher's PDF, also known as Version of record

Citation for published version (APA):

Anh, N. T. L., Madsen, H., Dalsgaard, A., Phuong, N. T., Thanh, D. T. H., \& Murrell, K. D. (2010). Poultry as reservoir hosts for fishborne zoonotic trematodes in vietnamese fish farms. Veterinary Parasitology, 169(3-4), 391-394. https://doi.org/10.1016/j.vetpar.2010.01.010 


\title{
Poultry as reservoir hosts for fishborne zoonotic trematodes in Vietnamese fish farms
}

\author{
Nguyen Thi Lan Anh ${ }^{\mathrm{a}, *}$, Henry Madsen ${ }^{\mathrm{b}}$, Anders Dalsgaard ${ }^{\mathrm{c}}$, Nguyen Thi Phuong ${ }^{\mathrm{a}}$, \\ Dao Thi Ha Thanh ${ }^{a}$, K. Darwin Murrell ${ }^{c}$ \\ ${ }^{a}$ National Institute of Veterinary Research, 86 Truong Chinh, Hanoi, Viet Nam \\ ${ }^{\mathrm{b}}$ DBL - Centre for Health Research and Development, Faculty of Life Sciences, University of Copenhagen, Thorvaldsensvej 57, 1871 Frederiksberg C, Denmark \\ ${ }^{\mathrm{c}}$ WHO/FAO Collaborating Centre for Parasitic Zoonoses, Department of Veterinary Disease Biology, Faculty of Life Sciences, \\ University of Copenhagen, Groennegaardsvej 15, DK-1870 Frederiksberg, Denmark
}

\section{A R T I C L E I N F O}

Article history:

Received 22 October 2009

Received in revised form 22 December 2009

Accepted 5 January 2010

\section{Keywords:}

Fishborne zoonotic parasites

Chicken

Duck

Reservoir hosts

Fish farm

Vietnam

\begin{abstract}
A B S T R A C T
Fishborne zoonotic trematodes (FZT) are widespread in Vietnam and Southeast Asia. It is now recognized that the risk of being infected from eating raw fish dishes applies not only to humans, but also to domestic animals (e.g., cats, dogs, and pigs) and fish-eating birds. The role of ducks and chicken, commonly raised on fish farms, as reservoir hosts, however, has not been adequately investigated. To study this question, chickens and ducks from integrated poultry-fish farms in Nghia Lac and Nghia Phu communes, Nam Dinh province, Vietnam were surveyed for FZT infections. A total of 50 ducks and 50 chickens from each commune were examined. Results revealed that $12 \%$ of chickens and $30 \%$ of ducks were infected with various species of trematodes, including two zoonotic species, Centrocestus formosanus and Echinostoma cinetorchis. Both occurred in chickens whereas only $E$. cinetorchis was found in ducks. Prevalence of these zoonotic species was $12 \%$ and $7 \%$ in ducks and chickens, respectively. Among other trematodes, Hypoderaeum conoideum, also a zoonotic fluke, was the most prevalent (20-30\%). The feeding of snails and fish remains to poultry, either intentionally or by discharge of waste from the slaughter of ducks and chickens into the ponds, was identified as risk factors for trematode infection. The FZT species and low prevalence found in poultry in these communes indicate their role as reservoir hosts is minor.
\end{abstract}

(c) 2010 Elsevier B.V. All rights reserved.

\section{Introduction}

Fishborne zoonotic trematodes (FZT) including liver and intestinal trematodes are increasingly being recognized as significant public health problem (Chai et al., 2005). The parasites are especially of concern to the fast growing aquaculture industries of Southeast Asia. Studies on freshwater fish were conducted in Vietnam and found that in the Mekong Delta, 1.2-29.7\% of cultured fish were infected with FZT metacercariae (Thu et al., 2007; Thien

\footnotetext{
* Corresponding author. Tel.: +84 4 8694505; fax: +84 48694082.

E-mail address: linhlananh2001@yahoo.com (N.T.L. Anh).
}

et al., 2009) whereas in the North, prevalence of FZT was $44.6 \%$ in Nghe An province (Chi et al., 2008) and was $>50 \%$ in Nam Dinh province (Van et al., in press).

The role of reservoir hosts for FZT in aquaculture systems has recently been demonstrated, including the importance of treatment of infected domestic animals for sustainable prevention and control of FZT in fish farms (Anh et al., 2009a,b). There are a wide range of potential definitive hosts in the life cycle of FZT, apart from humans, particularly domestic and wild animals and fish-eating birds (Chai et al., 2005; Schuster et al., 2007; Anh et al., 2009a). In Vietnam, chicken and duck are common poultry in Vietnamese fish farms. Ducks are often maintained in so-called VAC ponds (integration of vegetable, pond and 
animal husbandry farming) and chickens allowed to roam freely around ponds. Their role, however, in maintaining the life cycle of FZT in aquaculture systems is not understood. The aim of the study reported here was therefore to determine the prevalence of FZT in chickens and ducks in two northern Vietnam communes endemic for FZT. Greater knowledge on the role of poultry as reservoir hosts is needed to develop an effective integrated control program for FZT in fish aquaculture.

\section{Materials and methods}

\subsection{Sampling method}

From April to May 2009, a cross-sectional survey was conducted for FZT in ducks and chickens in Nghia Lac and Nghia Phu communes in Nam Dinh province which is located in northern Vietnam. A total of 33 and 27 fishfarming households from Nghia Phu and Nghia Lac communes, respectively, were randomly selected from a list of households and ducks and chickens purchased from them. A total of 6 of the selected households in Nghia Phu and 9 in Nghia Lac was included in a study on FZT infections in fish in 2006 (Van et al., in press). A total of 50 ducks and 50 chickens were surveyed, 5 ducks and 5 chickens per selected household if possible. If chickens and/or ducks were not reared in a selected household, the household was replaced by other randomly selected households. During sampling, farmers were asked questions about certain practices relating to poultry husbandry: where the poultry are fed, the types of commercial feeds fed, and whether snails and fish remains are used to feed the fish.

\subsection{Parasite recovery and identification}

The chickens and ducks were killed by exsanguinations from the neck vein and their intestines and livers removed to separate dishes containing saline. The livers were opened following the main tributaries of the biliary duct, and any visible trematodes picked out and, placed in a separate Petri-dish containing saline. Livers were cut into small, thin pieces and placed in saline for $10 \mathrm{~min}$, then crushed and filtered through a tea strainer (Anh et al., 2009a) and any visible trematodes observed were isolated. The intestines were opened and their contents were flushed with tap water into a cup, and then filtered through a tea strainer, visible trematodes were isolated and the intestinal contents remains were subsequently filtered through a $400 \mu \mathrm{m}$ mesh. The sieve retentate was then washed into a Petri-dish with saline and searched for minute trematodes under a stereomicroscope. The fluid that passed through the sieve was allowed to settle and the sediment also searched for trematodes. Finally, the intestine was cut into small pieces and placed in a bucket with warm saline for $1 \mathrm{~h}$ and the fluid then was poured into conical flasks. The sediment was subsequently allowed to settle for $30 \mathrm{~min}$, and then examined in Petri-dishes under a stereomicroscope.

All isolated trematodes from an individual chicken or duck were combined in one flask and fixed in hot 5\% formalin. After counting the number of trematodes recovered, all the trematodes were stained in Semichon's acetocarmine and identified with published keys (Yamaguti, 1971; Pearson and Ow-Yang, 1982; Jones et al., 2005).

\subsection{Statistical analysis}

Prevalence estimates for total trematode infections and for individual trematode species, by commune and animal species (chicken or duck) were compared using logistic regression adjusting for clustering within households. Similarly, intensity of infection for all trematode infections and for individual trematode species, were compared between communes and animal species after adjusting for clustering within households using negative binomial regression (Hilbe, 2006). The ancilliary parameter was estimated using a full maximum likelihood estimation and this was then specified in a generalized linear model as described in Hilbe (2006). Factors that were not significant were removed from the final model. Potential risk factors were then tested for significance by adding them one by one to these models. A P-value less than 0.05 were taken to indicate a significant difference.

\section{Results}

Prevalence of trematode species in chicken and duck in the two communes is presented in Table 1. Chickens were collected from 41 farms and ducks from 24 farms. Among them, $24 \%$ and $63 \%$ of the farms had infected chickens and ducks, respectively. Overall the prevalence of trematode infections (all species combined) was $12 \%$ and $30 \%$ in chickens and ducks, respectively. Two species were identified as fishborne zoonotic trematodes in chickens, Centrocestus formosanus and Echinostoma cinetorchis

Table 1

Prevalence (\%) of trematodes in chickens and ducks from the Nghia Lac and Nghia Phu communes.

\begin{tabular}{|c|c|c|c|c|}
\hline \multirow[t]{2}{*}{ Identified trematode species } & \multicolumn{2}{|c|}{ Nghia Lac commune } & \multicolumn{2}{|c|}{ Nghia Phu commune } \\
\hline & Chicken $n=50$ & Duck $n=50$ & Chicken $n=50$ & Duck $n=50$ \\
\hline Centrocestus formosanus & $2.0(1)$ & 0.0 & $4.0(7)$ & 0.0 \\
\hline Echinostoma cinetorchis & $2.0(1)$ & $4.0(1)$ & $6.0(13)$ & $20.0(14)$ \\
\hline Hypoderaeum conoideum & $4.0(2)$ & $14.0(2)$ & $12.0(20)$ & $28.0(36)$ \\
\hline Nigerina hardoiensis & 0.0 & 0.0 & 0.0 & $2.0(1)$ \\
\hline Notocotylus spp. & 0.0 & $2.0(1)$ & 0.0 & 0.0 \\
\hline Total & $8.0(2)$ & $18.0(2)$ & $16.0(32)$ & $42.0(45)$ \\
\hline
\end{tabular}

Numbers in parentheses are the maximum number of trematodes recovered in one animal. 
Table 2

Information on animal husbandry practices of chicken and duck relating to FZT infections based on interview farmers in Nghia Lac and Nghia Phu communes.

\begin{tabular}{|c|c|c|c|c|}
\hline \multirow[t]{2}{*}{ Characteristics } & \multicolumn{2}{|c|}{ Nghia Lac commune } & \multicolumn{2}{|c|}{ Nghia Phu commune } \\
\hline & Chicken $(n=20)$ & Duck $(n=10)$ & Chicken $(n=21)$ & Duck $(n=14)$ \\
\hline Free-roaming penned in fish pond & 18 & 10 & 20 & 14 \\
\hline Fed raw fish waste & 2 & 3 & 2 & 2 \\
\hline Fed snails & 5 & 8 & 4 & 13 \\
\hline $\begin{array}{l}\text { Waste from intestine of chickens and ducks } \\
\text { discharged directly into the fish pond }\end{array}$ & 20 & 10 & 21 & 14 \\
\hline
\end{tabular}

$n$ : number of integrated poultry-fish farm.

(Table 1). C. formosanus was not detected in ducks, but $E$. cinetorchis had a prevalence of $12 \%$ in ducks. Another zoonotic trematode, Hypoderaeum conoideum, was recovered from both chickens ( $8 \%$ ) and ducks (21\%). Two other trematodes, Nigerina hardoiensis and Notocotylus spp., were detected in $1 \%$ of ducks.

The odds of infection in ducks was 3.3 (95\% CI 1.457.50; $P<0.01$ ) times greater than that for chickens when adjusted for effect of commune and clustering within households. The odds of infection in Nghia Phu commune was 2.9 (95\% CI 1.35-6.16; $P<0.01)$ times greater than that in Nghia Lac commune. The interaction between animal species and commune was not statistically significant. For the specific FZT species, the odds of infection with $E$. cinetorchis in ducks was 3.4 (1.13$10.21 ; P<0.05)$ times greater than that for chickens when adjusting for commune effect and clustering within households.

Intensity of infection (total count of all trematodes) did not differ significantly between ducks and chickens when adjusted for commune, while counts in Nghia Phu were 17.8 times higher than those in Nghia Lac commune $(95 \%$ CI: 6.47-48.70; $P<0.001)$ when adjusted for clustering within households. Similarly, counts of E. cinetorchis did not differ significantly between ducks and chickens when adjusted for commune, while counts were higher in Nghia Phu than in Nghia Lac commune $(P<0.001)$.

In these farms, chickens were allowed to free roam around the premises, and ducks were generally confined to ponds. Snails were sometimes collected by the owners and fed to both the chickens and ducks (Table 2). Statistical analysis showed that feeding snails and feeding fish to chickens and ducks were risk factors for the infections in these animals. When the practice of feeding snails was added to the model as a risk factor, the differences between ducks and chickens were not significant and therefore host species was removed from the model. The odds of infection in the poultry fed snails was 4.1 (95\% CI: 1.59-10.35; $P<0.01)$ times that among animals not fed snails when adjusted for the effect of commune (OR: 3.07; 95\% CI: $1.4-$ 6.34; $P<0.01)$ and clustering within households. A similar model using intensity of infection showed that trematode counts in poultry fed snails were $7.6(2.39-24.10 ; P<0.01)$ times that for poultry not fed snails. Similarly, the odds of infection for poultry fed fish remains was 3.5 (1.58-7.66; $P<0.01)$ times that of poultry not fed fish remains after adjusted for effect of animal and commune and clustering within households. The corresponding count model showed no effect of host species, but the trematode counts were 2.7 (95\% CI: $1.33-5.52 ; P<0.01$ ) times higher in poultry fed fish remains than among those that were not. During preparation of chicken or duck for human consumption, all households reported that contents of intestines were washed directly into fishponds.

\section{Discussion}

The 4 species of intestinal trematodes recovered from chickens and ducks in this study are new records for these hosts in Vietnam. The FZT species C. formosanus and E. cinetorchis have been reported previously in dogs and cats in Vietnam by Anh et al. (2009b), although infections in humans have not been reported from Vietnam. C. formosanus metacercariae are relatively common in fish (Thien et al., 2007; Chi et al., 2008; Van et al., in press) and requires fish as second intermediate hosts. In contrast, E. cinetorchis and $H$. conoideum use either fish or snails as second intermediate hosts, a factor that might explain the higher prevalence of the latter species especially in ducks. Echinostome cercariae are commonly found in snails in these communes (Dung, 2007). To supply more calcium and nutrition for chickens and ducks (in all farms, ducks were raised for egg production), the feeding of snails is common practice by their owners. The higher prevalence of $E$. cinetorchis and $H$. conoideum in ducks may also be due to the practice of penning ducks in fish ponds and adjoining canals where access to infected snails is increased. In general, the access of chickens and ducks to fish or fish waste (e.g., intestine, scale, fins and gills) is an important risk factor since fish in these communes are commonly infected with FZT metacercariae (Van et al., in press).

Contamination of fish ponds by poultry with trematode eggs is facilitated by the belief on the part of owner's that poultry faeces is a good fish food. Further, the free-roaming practice for chickens may increase the transport of trematode eggs to water bodies containing snail intermediate hosts during rain and feces are washed into the ponds by surface water runoff.

The low prevalence of FZT species in the chickens and ducks suggests their role as reservoir hosts is not significant. The penning up of chickens and locating their houses as far as possible away from water bodies would be beneficial to preventing fish infections; this is probably not feasible for duck production in these farming communities, however. Instead, the potential for treatment of ducks with an appropriate anthelmithic should be investigated. In addition, fish farmers must be educated on the risks associated with feeding snails or raw fish 
waste to poultry and livestock as a component of any integrated FZT prevention and control program.

\section{Acknowledgements}

The "Fishborne Zoonotic Parasites in Vietnam" (FIBOZOPA) project no. 91140/file no. 104. Dan.L.8.f and the Danish International Development Assistance (Danida) are gratefully acknowledged for their financial support of this study. We would like to thank Eric Hoberg and Patrica Pillit of the National Parasite Collection, ARS-USDA, Beltsville, Maryland and Mike Kinsella, Missoula, Montana for important assistance in the identification of the trematodes. We are also grateful to the staff at the FIBOZOPA project office for administrative help and to the farmers in Nghia Lac and Nghia Phu communes in Nam Dinh province for their collaboration.

\section{References}

Anh, L.T.N., Phuong, T.N., Murrell, K.D., Johansen, M.V., Dalsgaard, A., Thu, T.L., Chi, K.T.B., Thamsborg, S.M., 2009a. Animal reservoir hosts and fish-borne zoonotic trematode infections on fish farms, Vietnam. Emerg. Infect. Dis. 15, 540-546.

Anh, L.T.N., Phuong, T.N., Johansen, M.V., Murrell, K.D., Van, T.P., Dalsgaard, A., Thu, T.L., Thamsborg, S.M., 2009b. Prevalence and risks for fishborne zoonotic trematode infections in domestic animals in a highly endemic area of North Vietnam. Acta Trop. 112, 198-203.
Chai, J.Y., Murrell, K.D., Lymbery, A.J., 2005. Fish-borne parasitic zoonoses: status and issues. Int. J. Parasitol. 35, 1233-1254.

Chi, T.T.K., Dalsgaard, A., Turnbull, J.F., Tuan, P.A., Murrell, K.D., 2008 Prevalence of zoonotic trematodes in fish from Vietnamese fishfarming community. J. Parasitol. 94, 423-428.

Dung, T.B., 2007. Distribution and larval trematode infection of freshwater snails in two communes, Nghia Lac and Nghia Phu, Nam Dinh Province, Vietnam. MSc Thesis. Faculty of Life Sciences, University of Copenhagen, Denmark.

Hilbe, J.M., 2006. Negative binomial regression. Cambridge University Press, Cambridge, UK, $251 \mathrm{p}$.

Jones, A., Bray, R.A., Gibson, D.I., 2005. Keys to the Trematoda, vol. 2. CABI Publishing, Oxforshire, UK, pp. 734.

Pearson, J.C., Ow-Yang, C.K., 1982. New species of Haplorchis from Southeast Asia, together with keys to the Haplorchis-group of heterophyid trematodes of the region. Southeast Asian J. Trop. Med. Public Health 13, 35-60.

Schuster, R.K., Heidrich, J., Pauly, A., Nockler, K., 2007. Liver flukes in dogs and treatment with praziquantel. Vet. Parasitol. 150, 362-365.

Thien, C.P., Dalsgaard, A., Thanh, N.B., Olsen, A., Murrell, K.D., 2007 Prevalence of fishborne zoonotic parasites in important cultured fish species in Mekong Delta, Vietnam. Parasitol. Res. 101, 1277-1284.

Thien, C.P., Dalsgaard, A., Nhan, T.N., Olsen, A., Murrell, K.D., 2009. Prevalence of zoonotic trematode parasites in fish fry and juveniles in fish farms of the Mekong Delta, Vietnam. Aquaculture 295, 1-5.

Thu, N.D., Dalsgaard, A., Loan, L.T.T., Murrell, K.D., 2007. Survey for zoonotic liver and intestinal trematode metacercariae in cultured and wild fish in An Giang Province, Vietnam. Kor. J. Parasitol. 45, 4554.

Yamaguti, S., 1971. Synosis of Digenetic Trematodes of Vertebrates, vol. 1. Keigaku Publishing Comparany, Tokyo.

Van, T.P., Ersboll, K.A., Te, Q.B., Hang, T.N., Murrell, D., Dalsgaard, A., in press. Fishborne zoonotic trematodes in cultured and wild-caught freshwater fish from the Red River Delta, Vietnam. Vector-borne and Zoonotic Dis. 